interactions and teaching have improved as new elements have been added to these days, and with exposure and practice in this new way of working.

Recommendations The Graduate Team found interactions and reflections from learners are more readily offered up where there are a variety of ways to present these, rather than solely having to speak on camera to their teacher and peers, and would recommended incorporating these into virtual learning programmes.

\section{COMMUNITY SPEECH AND LANGUAGE THERAPISTS' VIEWS OF REPORTS FROM THE NEURODEVELOPMENTAL ASSESSMENT CLINIC AT GREAT ORMOND STREET HOSPITAL}

${ }^{1}$ Abigail Mance, ${ }^{2}$ Phoebe Martin. ${ }^{1}$ Great Ormond Street Hospital; ${ }^{2}$ UCL

10.1136/archdischild-2020-gosh.57

The Neurodevelopmental Assessment Clinic (NAC) at GOSH is a multi-disciplinary, tertiary level service which provides specialist expertise in the assessment of children with complex neurodevelopmental disorders and provides diagnostic opinions regarding autism, language disorder, intellectual disability, ADHD. At the end of each child's assessment, NAC gives a summary report to parents and key professionals such as the child's community Speech and Language Therapist (SLT). Community SLTs have an important role carrying out therapy and providing advice and support to children's schools and parents/carers.

The aim of this study was to evaluate whether the summary reports prepared by NAC are an effective way of communicating the clinic's key findings and recommendations to community SLTs. This study was carried out by Phoebe Martin, UCL MSc student, supervised by Abigail Mance, GOSH SLT and Dr Carol Sacchett, Principal Teaching Fellow at UCL.

A survey was given to twelve community SLTs and one further telephone interview was completed. Thematic analysis methods were used to analyse the data. Fifteen paediatricians' (referrers) opinions, gathered from a previous study, were used for comparison.

Overall NAC's reports were valued by the community SLTs as they added to their knowledge and they reported the recommendations in the reports were realistic. Thematic analysis showed that resources such as time and what the local service could offer were both facilitators and barriers to implementing recommendations. External factors also had implications for the implementation of recommendations. Higher alignment between NAC's recommendations and community SLT services' resources, such as time and staffing, increased the likelihood of the recommendations being implemented.

Further investigation of how useful other key professionals in the community such as teachers find the reports from NAC is recommended.

\section{BIOETHICS SUPPORT IN A TERTIARY CHILDREN'S HOSPITAL DURING THE COVID-19 PANDEMIC}

\footnotetext{
${ }^{1}$ Sarah Aylett, ${ }^{2}$ Anne MacNiven, ${ }^{2}$ Mariana Dittborn, ${ }^{3}$ Dave Archard, ${ }^{2}$ James Linthicum, ${ }^{2}$ Vic Larcher, ${ }^{1}$ Joe brierley. ${ }^{1}$ Great Ormond Street Hospital and University College London; ${ }^{2}$ Great Ormond Street Hospital; ${ }^{3}$ Queen's University, Belfast
}

During a pandemic, ethical concerns arise in relation to allocation of resources for seriously ill patients. The COVID-19 pandemic predominantly affected adults with a high associated morbidity and mortality, however it was anticipated that there would also be an impact on the paediatric population. There were four phases to the work of the Paediatric Bioethics Centre (PBC) service at GOSH:

1.Preparation: Documents to support/guide hospital teams and regional inpatient, community and hospice settings were prepared with colleague. We adapted existing 'ethics support' mechanisms to combat workforce moral distress, distress/injury.

2.Bioethics activity: was highest in the rapid response service where difficult treatment decisions were considered with clinical teams, families and young people. 12 reviews were carried out from March- May to consider experimental antiviral treatment, allocation of resources in the context of COVID-19 and non Covid cases considering a ceiling of treatment. Telemedicine facilitated the rapid response to these urgent cases and involved parents, including those not in the hospital.

3.Education: the service provided 'pandemic webcasts' on decision-making and broader child-health concerns. Staff support with other wellbeing services has been essential, especially for those deployed to overwhelmed local adult ICUs.

4. Reflection: focussed on (a) Research Re future deployment to minimise moral distress/injury, b) remote video-conferencing - parents/participants experience/ability to consider complex ethical issues and c) role of faith/non-faith in society's recovery.

This work illustrates the importance of the role of the Paediatric Bioethics Service in a tertiary children's hospital during the COVID-19 pandemic.

\section{THE IMPACT OF THE COVID-19 PANDEMIC ON THE PROVISION OF CHILDREN'S HEALTHCARE- CONSIDERATION OF THE ETHICAL ASPECTS}

${ }^{1}$ Sarah Aylett, ${ }^{2}$ Anne MacNiven, ${ }^{2}$ Mariana Dittborn, ${ }^{3}$ Dave Archard, ${ }^{2} J a m e s$ Linthicum, ${ }^{2}$ Vic Larcher, ${ }^{1}$ Joe brierley. ${ }^{1}$ Great Ormond Street Hospital and University College London; ${ }^{2}$ Great Ormond Street Hospital; ${ }^{3}$ Queen's University, Belfast

\subsection{6/archdischild-2020-gosh.59}

The major impact of the COVID-19 pandemic has been on the health of adults. A small percentage of children have been acutely ill with COVID-19. Urgent reconfiguration of services with centralisation of paediatrics to free up resources for ill adults was carried out in North Thames and routine paediatric services at GOSH and in other Trusts curtailed. During a pandemic, the rights and interests of individuals can be trumped by a utilitarian approach to the provision of services such as health, education and social welfare. However, the ethical aspects of the impact of this on children's health requires consideration. Arguably, children have been the bystanders to this process without involvement of young people in planning these changes (Larcher and Brierley 2020). Children have not been able to access treatment locally and visiting was limited to one adult, even for those children with serious, life threatening illness. Face to face outpatient consultations for ill children have not been accessible and community AHPs and services for children with chronic disease and disability have not been available 